\title{
Diffuse Calcinosis from Total Thyroidectomy and Secondary Hypocalcaemia
}

\author{
Filipa Leal, Luís Nogueira, Teresa Martins Mendes, Ana Silva Rocha, Dinis Sarmento, Francisco Pombo, Bárbara Silva \\ Centro Hospitalar do Tâmega e Sousa, Penafiel, Portugal
}

Doi: 10.12890/2021_002489- European Journal of Case Reports in Internal Medicine - C EFIM 2021

Received: 15/03/2021

Accepted: 20/03/2021

Published: $27 / 05 / 2021$

How to cite this article: Leal F, Nogueira L, Martins Mendes T, Silva Rocha A, Sarmento D, Pombo F, Silva B. Diffuse calcinosis from total thyroidectomy and secondary hypocalcaemia. EJCRIM 2021;8: doi:10.12890/2021_002489.

Conflicts of Interests: The authors disclose no conflicts of interest.

This article is licensed under a Commons Attribution Non-Commercial 4.0 License

\section{ABSTRACT}

Hypoparathyroidism is a rare endocrine disorder and its main cause is cervical surgery such as thyroidectomy. The incidence of hypoparathyroidism after total thyroidectomy varies, and is reported to be between 0.3 and $6.3 \%$. In terms of brain imaging, hypoparathyroidism can cause calcification mainly of the basal ganglia, with other areas rarely affected. Concerning extracerebral calcification, few studies have investigated the prevalence of visceral calcifications.

We describe a case of a woman with secondary hypocalcaemia who presented with a transient ischaemic attack (TIA) and the investigation revealed an extensive calcinosis of the brain and the vascular structures responsible for the event.

\section{LEARNING POINTS}

- latrogenic hypoparathyroidism with hypocalcaemia is an important complication of total thyroidectomy. Hypocalcaemia manifestations can vary from asymptomatic to life-threatening conditions.

- Hypoparathyroidism (with hypocalcaemia) can cause cerebral calcification mainly of basal ganglia, with other areas of the brain rarely affected.

- Extracerebral calcifications are under-studied.

\section{KEYWORDS}

Hypoparathyroidism, cerebral calcifications, brain calcinosis syndrome

\section{CASE DESCRIPTION}

We present the case of a 73-year-old woman with a history of hypertension, hypothyroidism and hypocalcaemia secondary to a thyroidectomy over 20 years previously. She was supposedly medicated with levothyroxine and calcium and vitamin D supplements but with non-compliance to treatment. She attended the emergency department after 2 transitory episodes (10 minutes' duration each) of speech disturbance and left motor deficit. The computed tomography (CT) scan showed extensive chronic calcification of central cerebral and cerebellar nuclei, of Virchow-Robin spaces and the calcarine sulcus (Figs. 1-3). Additional investigation revealed severe hypocalcaemia, hyperphosphataemia, vitamin D deficit and hypoparathyroidism; the cervical Doppler examination revealed a stenosis of more than $90 \%$ of the internal carotids, bilaterally. We additionally performed a body CT scan that revealed extensive calcification of the aorta (Fig. 4) and both renal arteries which was complemented with a Doppler ultrasound that revealed haemodynamically significant stenosis of both renal arteries, but no significant changes in flow.

The diagnosis of transient ischaemic attack was made and the patient was submitted to a right carotid endarterectomy, without complications. Furthermore, we initiated supplementation of vitamin D, calcium and levothyroxine to correct the metabolic changes.

In addition, bilateral renal stenosis contributes to hypertensive disorder and the additional risk of cardiovascular diseases, so she was evaluated for vascular surgery but with no indication for surgical treatment. 


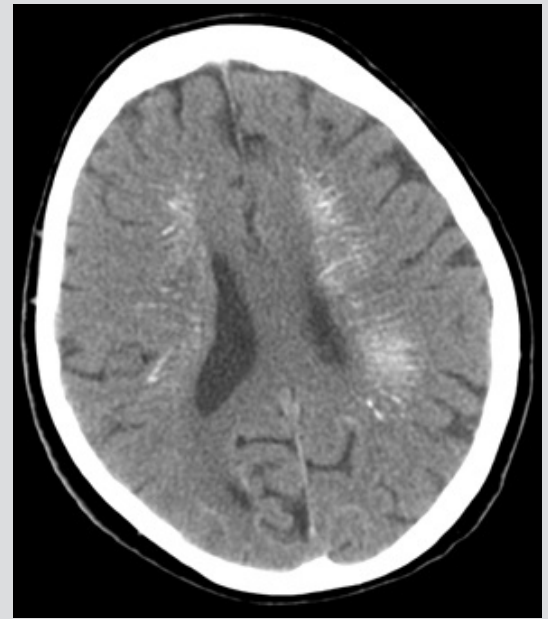

Figure 1. Diffuse periventricular calcification

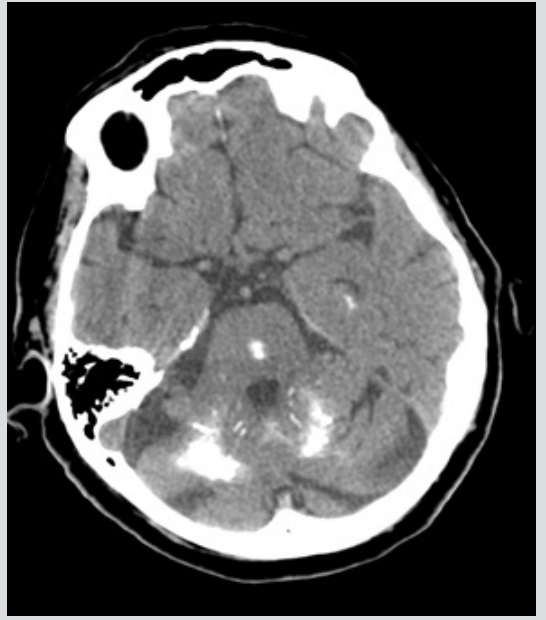

Figure 2. Cerebellar nuclei calcification

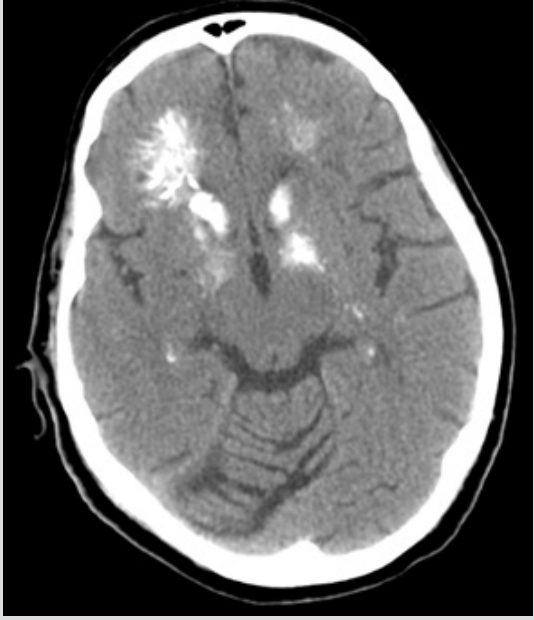

Figure 3. Basal ganglia calcification

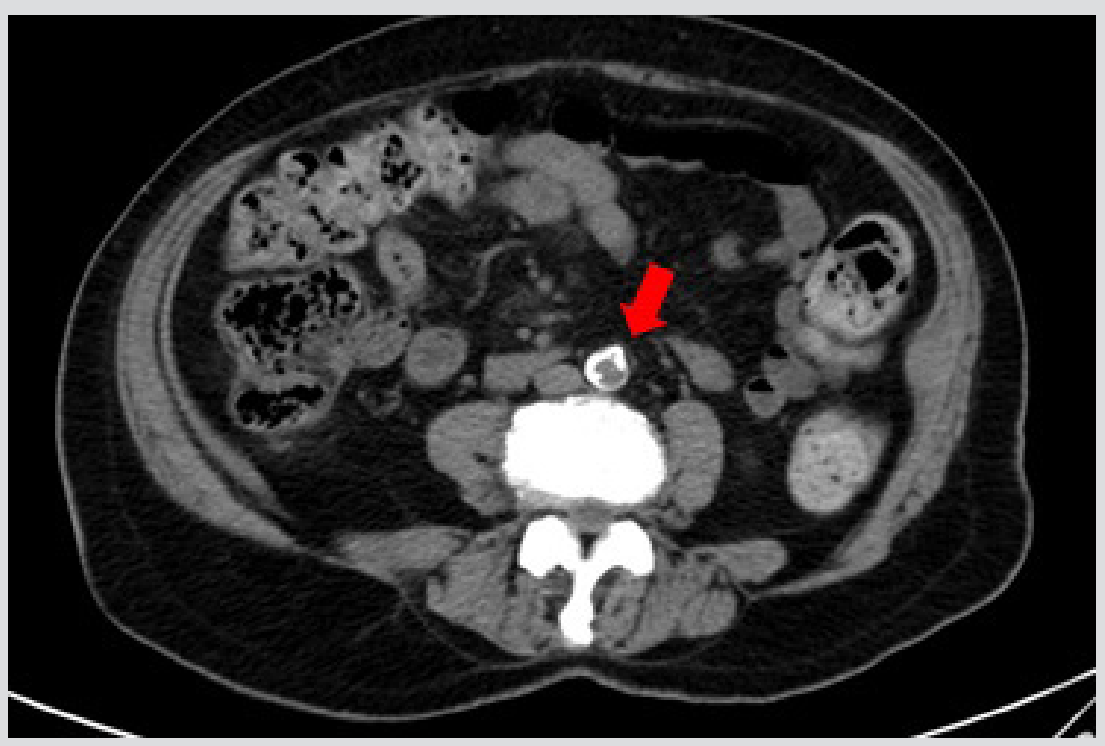

Figure 4. Extensive aortic calcification

\section{DISCUSSION}

latrogenic hypoparathyroidism with hypocalcaemia is an important complication of total thyroidectomy and can vary from asymptomatic to life-threatening conditions ${ }^{[1-4]}$. In terms of intracranial calcifications, it is rare to reach structures beyond the basal ganglia and the cerebellum ${ }^{[2,4-8]}$; however, in addition to the calcifications of the basal ganglia, our patient presented calcification of other structures such as the calcarine sulcus. The intracerebral changes, mainly in the basal ganglia, can culminate in the development of extrapyramidal syndromes or dementia ${ }^{[5,6]}$.

Although there are few data on extracerebral calcifications for this type of patient ${ }^{[2]}$, our case showed an extensive calcification of vascular structures such as the carotid, aortic and renal arteries.

The case illustrates the importance of follow-up for this type of patient, since the early recognition of complications such as hypothyroidism and its corrected treatment can prevent further consequences and obviate permanent damage. 


\section{REFERENCES}

1. Abate EG, Clarke BL. Review of hypoparathyroidism. Front Endocrinol 2017;7:172.

2. Lorente-Poch L, Rifà-Terricabras S, Sancho JJ, Torselli-Valladares D, González-Ortiz S, Sitges-Serra A. Prevalence of basal ganglia and carotid artery calcifications in patients with permanent hypoparathyroidism after total thyroidectomy. Endocr Connect 2020;9(10):955-962.

3. Cooper MS, Gittoes NJ. Diagnosis and management of hypocalcaemia. BMJ 2008;336(7656):1298-1302.

4. Mitchell DM, Regan S, Cooley MR, Lauter KB, Vrla MC, Becker CB, et al. Long-term follow-up of patients with hypoparathyroidism. J Clin Endocrinol Metab 2012;97(12):45074514.

5. Zisimopoulou V, Siatouni A, Tsoukalos G, Tavernarakis A, Gatzonis S. Extensive bilateral intracranial calcifications: a case of iatrogenic hypoparathyroidism. Case Rep Med 2013;2013:932184.

6. Agarwal R, Lahiri D, Biswas A, Mukhopadhyay J, Maity P, Roy MK. A rare cause of seizures, parkinsonian, and cerebellar signs: brain calcinosis secondary to thyroidectomy. N Am J Med Sci 2014;6(10):540-542.

7. Donzuso G, Mostile G, Nicoletti A, Zappia M. Basal ganglia calcifications (Fahr's syndrome): related conditions and clinical features. Neurol Sci 2019;40(11):2251-2263.

8. Lines SW, Ramadan H. Looking beyond the obvious: cerebral calcification. Pract Neurol 2013;13(6):386-387. 